\title{
Focused Antenatal Care Service Utilization and Associated Factors in Damot Sore District, Southern Ethiopia, Community Based Cross Sectional Study
}

\author{
Abera Beyamo, ${ }^{1, *}$, Wolde Facha ${ }^{1}$, Alemu Lire ${ }^{2}$ \\ ${ }^{1}$ School of Public Health, College of Health Sciences and Medicine, WolaitaSodo University, WolaitaSodo, Ethiopia \\ ${ }^{2}$ Hadiya Zone Health Department, Hadiya Zone, Ethiopia
}

\section{Email address:}

woldiefacha@gmail.com (W. Facha),bdereje05@gmail.com (A. Beyamo), dilolombamo@gmail.com (A. Lire)

${ }^{*}$ Corresponding author

\section{To cite this article:}

Abera Beyamo, Wolde Facha, Alemu Lire. Focused Antenatal Care Service Utilization and Associated Factors in Damot Sore District, Southern Ethiopia, Community Based Cross Sectional Study. American Journal of Health Research. Vol. 5, No. 6, 2017 , pp. 167-172. doi: 10.11648/j.ajhr.20170506.11

Received: August 8, 2017; Accepted: September 18, 2017; Published: October 23, 2017

\begin{abstract}
One of the important factors in reducing maternal morbidity and mortality is focused antenatal care which considers every pregnant woman who was at high risk for developing pregnancy related complications. Hence, all pregnant women should receive at least four antenatal visits to early identify the complications and intervene accordingly. The study aimed to assess focused antenatal care service utilization and associated factors among mothers who gave birth within 6 month preceding the study in Damot Sore District. A community based cross sectional study was conducted using quantitative methods in April, 2017 in Damot Sore District. Study participants were selected by simple random sampling method from the sampling frame. Data were entered into Epidata 3.1 and exported to SPSS version 20 for analysis, and Bivariate and multivariable analysis was used to identify predictors of focused antenatal care service utilization. Variables with odds ratio $<=0.05$ in multivariable analysis were taken as independent predictors. A total of 490 mothers who have history of antenatal care for their last birth within 6 month preceding the study period were included in the study and 229(46.7\%) mothers attended focused antenatal care service. Maternal age (25-34) (AOR=1.92, 95\%CI: 1.20, 3.09), husbands occupation (AOR=1.92, $95 \%$ CI: $1.30,2.83$ ) and women empowerment $(\mathrm{AOR}=2.13,95 \% \mathrm{CI}: 1.43,3.20)$ were significantly associated with focused antenatal care service utilization. The majority of pregnant mothers did not attend focused antenatal care during their last pregnancy. Maternal age, husband's occupation and empowerment were identified as factors affecting focused antenatal care service utilization. Provision of focused antenatal care should be used as an opportunity for early detection of pregnancy related complications.
\end{abstract}

Keywords: Focused, Antenatal Care, Antenatal Care Service Utilization, Ethiopia

\section{Introduction}

Focused antenatal care (FANC) recognizes that every pregnant woman is at risk for complications, and therefore should receive basic care so as to prevent complications, facilitate early detection and treatment of complications [1]. Focused antenatal care recommends that all health pregnant women should have a minimum of four scheduled comprehensive antenatal visits during pregnancy. It is guided by five principles which are quality of care rather than quantity of visits, individualized care, disease detection contrary to risk categorization, evidence based practices, and birth/complication readiness. During their visits, women are counselled on topics such as birth preparedness, complication readiness, danger signs, nutrition, exclusive breastfeeding, and family planning. Women are also immunised against tetanus. They are tested and treated for anaemia, malaria, human immunodeficiency virus/acquired immune deficiency syndrome (HIV/AIDS), and sexually transmitted infections (STIs). The FANC model suggests that visits should take place before 16 weeks, between 16 and 28 weeks, at 28-32 weeks, and about 36 weeks [2]. Early detection of problems 
in pregnancy leads to more timely referrals for women in high risk categories or with complications; this is particularly true in Ethiopia, where three-quarters of the population live in rural areas and where physical barriers pose a challenge to providing health care [3]. Maternal and newborn mortality cost the world economy estimated $\$ 15$ Billion in lost productivity each year [4, 5]. Antenatal care is more beneficial in preventing adverse pregnancy outcomes when received early in the pregnancy and continued through delivery. World Health Organization (WHO) recommends that a woman without complications should have at least four antenatal care visits, the first of which should take place during the first trimester [4]. Globally in 2015 World Health Organization (WHO) estimates that 302,000 maternal deaths occurred as result of pregnancy and childbirth-related complications each year, with $99 \%$ of these deaths occurring in developing countries. With sub-Saharan Africa alone accounting for roughly 66\% (201000), followed by Southern Asia (66,000). With sub-Saharan Africa, the estimated maternal mortality ratio is 500 per 100,000 live births. More than $60 \%$ of all maternal deaths were contributed by ten countries; Ethiopia is one of them [5-7]. In Ethiopia, according to EDHS 2016 report maternal mortality ratio is estimated about 412 deaths per 100,000 life birth. The Sustainable Development Goals target a global maternal mortality ratio not greater than 70 maternal deaths per 100 000 live births by 2030 [8]. In Ethiopia, even if there is improvement in maternal health care service utilization including antenatal care; most of the women did not attend minimum number of visit recommended by World Health Organization [9-11]. Therefore, this study is intended to assess factors affecting FANC utilization among women who gave birth in Damot Sore District, Southern Ethiopia. The study will benefit Damot Sore District health office for improvement and effective interventions of maternal health services for the district population and findings will be relevant and useful for reproductive health planners and implementers of the program. This study will also assist in giving inputs to policy makers to use it as a base line for their future interventions and activities. It is the first study in the area so; it will benefit as a base line for future researcher.

\section{Method and Materials}

\subsection{Study Design Period and Area}

This community based cross sectional study was conducted in Damot Sore District in April, 2017. The District is one of the 13 Districts in the Wolaita Zone which is 18.5 $\mathrm{km}$ away from zonal town, Wolaita Sodo.

\subsection{Study Population and Sampling}

All mothers who gave birth in the last 6 months prior to the study in Damot Sore District were considered as source population and sampled mothers who gave birth in the last 6months prior to the study in Damot Sore District. Sample size was determined by using single population proportion formula; considering $12 \%$ proportion of focused antenatal care service use [9], 3\% margin of error and $10 \%$ estimated non-response rate then, the required minimum sample size calculated was495. First seven kebeles were randomly selected out of 20 kebeles and then all women who gave birth in the last 6 months prior to the study were selected from sampling frame of family folder found at health post. Sample was allocated to each kebele by proportional allocation to their population size. Finally the study participants were selected by simple random sampling method from the sampling frame.

\subsection{Data Collection Instrument and Data Collectors}

Data were collected by face-to-face interview using structured and pre-tested questionnaires. The questionnaires have embodied socio-demographic characteristics, obstetric history and service delivery patterns. Six midwives and two BSc nurses were participated during data collection and supervision process respectively.

\subsection{Data Processing}

The quality of data was assured by proper designing and pre-testing of the questionnaires to ensure consistency. The questionnaires were first prepared in English and translated to Wolaitato (local language). Finally, it was translated back to English by another person and training was given for both data collectors and supervisors by the principal investigators. The training included discussion on the objectives of the study, contents of the questionnaires, data collection techniques and issues of confidentiality of the responses. Questionnaires were reviewed and checked for completeness by the supervisors and the principal investigators and the necessary feedbacks were offered to data collectors throughout the study daily. All the questionnaires were checked visually, coded and entered into EPI info version 6 and were exported to SPSS version 20 software packages for analysis.

\subsection{Data Analysis}

Descriptive analysis was carried out for each of the variables to check frequency, distribution and missing value. Bivariate analysis was employed to check crude association between focused antenatal care service use and independent variables. Chi-square test was conducted to see variables fulfilling assumption. Variable with $\mathrm{p}$ value $<0.25$ on bivariate analysis was entered to binary logistic regression to identify the factors that affect focused antenatal care utilization. Odds ratio and corresponding 95\% confidence intervals was used to quantify the degrees of association between independent variable and the outcome variable. Results with $p$-value $\leq 0.05$ were considered as being statistically significant and the rest was refuted. Multicollinearity among independently associated variables was checked by multicollinearity diagnostic test VIF in linear regression and none was collinear. 


\section{Results}

\subsection{Socio-demographic Characteristics}

The study participants of this study were 490 with response rate of $99 \%$. From the study participants
253(51.6\%), 482(98.4\%) and 283(58.6\%) were orthodox religion followers, married and housewife respectively. Most of the study participants $342(69.8 \%$ ) were within the age group of 25-34 years. (Table 1)

Table 1. Socio-demographic characteristics of the study population in Damot Sore District, April 2017.

\begin{tabular}{|c|c|c|}
\hline Variable & Frequency & Percent \\
\hline \multicolumn{3}{|l|}{ Age } \\
\hline $15-24$ & 106 & 21.6 \\
\hline $25-34$ & 342 & 69.8 \\
\hline$>=35$ & 42 & 8.6 \\
\hline \multicolumn{3}{|l|}{ Religion } \\
\hline Orthodox & 197 & 40.2 \\
\hline Protestant & 253 & 51.6 \\
\hline Catholic & 40 & 8.2 \\
\hline \multicolumn{3}{|l|}{ Marital status } \\
\hline Married & 482 & 98.4 \\
\hline Divorced & 8 & 1.6 \\
\hline \multicolumn{3}{|l|}{ Maternal occupation } \\
\hline Housewife & 283 & 58.6 \\
\hline Student & 27 & 5.5 \\
\hline Gov't employee & 15 & 3.1 \\
\hline Private employee & 156 & 31.8 \\
\hline Daily labourer & 5 & 1.0 \\
\hline \multicolumn{3}{|l|}{ Husband's education } \\
\hline No formal education & 123 & 25.1 \\
\hline Formal education & 367 & 74.9 \\
\hline \multicolumn{3}{|l|}{ Husband's occupation } \\
\hline Farmer & 263 & 53.7 \\
\hline Other & 227 & 46.3 \\
\hline \multicolumn{3}{|c|}{ Have own income source } \\
\hline Yes & 178 & 36.3 \\
\hline No & 312 & 63.7 \\
\hline
\end{tabular}

\subsection{Focused Antenatal Care Service Utilization}

From the study participants $369(75.3 \%), 334(68.2 \%)$ and $233(47.6 \%)$ were got TT vaccine, HIV test, and de-worming services respectively. About 390(79.6\%), 445(91.0\%), 400(81.6\%) and 304(62.0\%), were got counselling on personal hygiene, breast feeding, family planning and immunization respectively. (see table 2 below)

Table 2. shows the focused antenatal care services utilization in Damot Sore woreda 2017.

\begin{tabular}{|c|c|c|c|c|}
\hline s. no & Variables & & Number & Percent \\
\hline \multirow{2}{*}{1} & \multirow{2}{*}{ TT vaccine } & Yes & 369 & 75.3 \\
\hline & & No & 121 & 24.7 \\
\hline \multirow{2}{*}{2} & \multirow{2}{*}{ HIV test } & Yes & 334 & 68.2 \\
\hline & & No & 156 & 31.8 \\
\hline \multirow{2}{*}{3} & \multirow{2}{*}{ De worming } & Yes & 233 & 47.6 \\
\hline & & No & 257 & 52.4 \\
\hline \multirow{2}{*}{4} & \multirow{2}{*}{ Got counselling on personal hygiene } & Yes & 390 & 79.6 \\
\hline & & No & 100 & 20.4 \\
\hline \multirow{2}{*}{5} & \multirow{2}{*}{ Got counselling on breast feeding } & Yes & 445 & 91.0 \\
\hline & & No & 45 & 9.0 \\
\hline \multirow{2}{*}{6} & \multirow{2}{*}{ Got counselling on family planning } & Yes & 400 & 81.6 \\
\hline & & No & 90 & 18.4 \\
\hline \multirow{2}{*}{7} & \multirow{2}{*}{ Got counselling on immunization } & Yes & 412 & 84.1 \\
\hline & & No & 78 & 15.9 \\
\hline
\end{tabular}

From the study participants 229(46.7\%) were got focused antenatal care service. (Figure 1) 


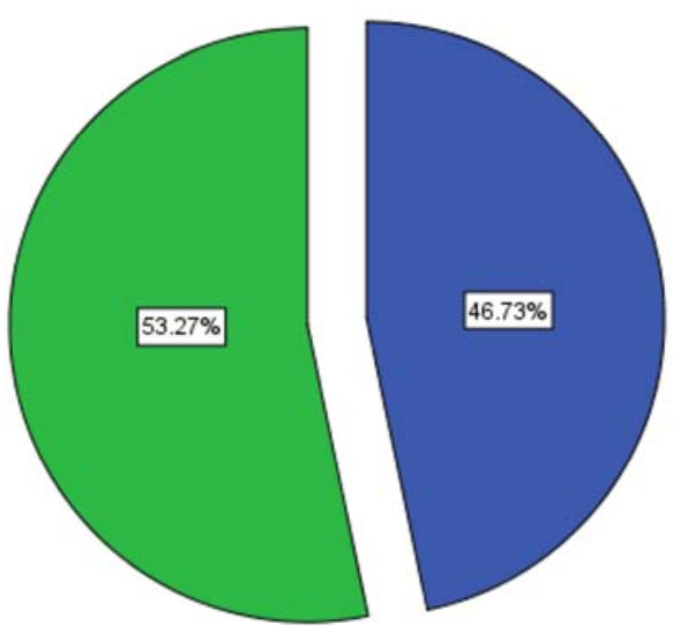

Figure 1. Shows utilization of focused antenatal care service in Damot Sore woreda, 2017.

\subsection{Bivariate Analysis of Focused Antenatal Care Service Utilization}

Variables showing crude association and selected for further analysis in multivariable logistic regression were; empowerment, maternal age, marital status, maternal occupation, fathers occupation, fathers education and mothers education. (Table 3)

Table 3. Bivariate binary logistic regression analysis of associated factors with FANC utilization in Damot Sore District, April 2017 (N)=490.

\begin{tabular}{|c|c|c|c|c|}
\hline \multirow{2}{*}{ Variables } & \multicolumn{2}{|c|}{ Utilized FANC service } & \multirow{2}{*}{$\operatorname{COR}(95 \% \mathrm{CI})$} & \multirow{2}{*}{ p-value } \\
\hline & Yes & No & & \\
\hline \multicolumn{5}{|l|}{ Due to long distance } \\
\hline Yes & $59(12.0 \%)$ & $45(9.2 \%)$ & 1 & \multirow[t]{2}{*}{0.499} \\
\hline No & $170(34.7 \%)$ & $216(44.1 \%)$ & $0.77(0.36,1.65)$ & \\
\hline \multicolumn{5}{|l|}{ Empowerment } \\
\hline Yes & $103(21.0 \%)$ & $69(14.1 \%)$ & $0.50(0.30,0.64)$ & \multirow[t]{2}{*}{0.001} \\
\hline No & $126(25.7 \%)$ & $139(39.2 \%)$ & 1 & \\
\hline \multicolumn{5}{|l|}{ Decision } \\
\hline Yes & $208(42.4 \%)$ & $228(46.5 \%)$ & 1 & \multirow[t]{2}{*}{0.272} \\
\hline No & $21(4.3 \%)$ & $33(6.7 \%)$ & $0.67(0.39,12.4)$ & \\
\hline \multicolumn{5}{|l|}{ Maternal age } \\
\hline $15-24$ & $65(13.3 \%)$ & $41(8.4 \%)$ & 1 & \multirow{3}{*}{$\begin{array}{l}0.022 \\
0.757\end{array}$} \\
\hline $25-34$ & $147(30.0 \%)$ & $195(39.8 \%)$ & $0.43(0.21,0.89)$ & \\
\hline$\geq 35$ & $17(3.5 \%)$ & $42(8.6 \%)$ & $0.90(0.47,1.73)$ & \\
\hline \multicolumn{5}{|l|}{ Marital status } \\
\hline Married & $225(45.9 \%)$ & $257(46.7 \%)$ & 1 & \multirow{2}{*}{0.852} \\
\hline Divorced & $4(0.8 \%)$ & $4(0.8 \%)$ & $0.88(0.21,3.54)$ & \\
\hline \multicolumn{5}{|l|}{ Maternal occupation } \\
\hline Housewife & $107(21.8 \%)$ & $180(36.7 \%)$ & $2.53(1.75,3.66)$ & \multirow[t]{2}{*}{0.001} \\
\hline Others & $112(24.9 \%)$ & $91(16.5 \%)$ & 1 & \\
\hline \multicolumn{5}{|l|}{ Husband's occupation } \\
\hline Farmer & $96(19.6 \%)$ & $167(34.1 \%)$ & $2.46(1.71,3.54)$ & \multirow[t]{2}{*}{0.001} \\
\hline Others & $133(27.1 \%)$ & $94(19.2 \%)$ & & \\
\hline \multicolumn{5}{|l|}{ Husband's education } \\
\hline Formal education & $191(39.0 \%)$ & $176(35.9 \%)$ & $2.47(1.62,3.75)$ & \multirow[t]{2}{*}{0.001} \\
\hline No formal education & $38(17.3 \%)$ & $85(7.8 \%)$ & 1 & \\
\hline \multicolumn{5}{|l|}{ Maternal education } \\
\hline Formal education & $187(38.2 \%)$ & $168(34.3 \%)$ & $2.43(1.57,3.75)$ & \multirow[t]{2}{*}{0.001} \\
\hline No formal education & $42(8.6 \%)$ & $93(19.0 \%)$ & 1 & \\
\hline
\end{tabular}

\subsection{Factors Independently Associated with Focused Antenatal Care Service Utilization}

The variables which has independently significant association with focused antenatal care service utilization were 
empowerment, maternal age (25-34) and husband's occupation. (Table 4)

Table 4. Factors independently associated with FANC service utilization in Damot Sore District, Wolaita Zone, Southern Ethiopia, April 2017.

\begin{tabular}{|c|c|c|c|c|c|}
\hline \multirow{2}{*}{ Variable $(N)=490$} & \multicolumn{5}{|c|}{ Utilized FANC service } \\
\hline & Yes & No & COR(95\%CI) & $\operatorname{AOR}(95 \% \mathrm{CI})$ & p-value \\
\hline \multicolumn{6}{|l|}{ Empowerment } \\
\hline Yes & $103(21.0 \%)$ & $69(14.1 \%)$ & $0.499(0.30,0.64)$ & $2.13(1.43,3.20)$ * & 0.001 \\
\hline No & $126(25.7 \%)$ & $139(39.2 \%)$ & 1 & & \\
\hline \multicolumn{6}{|l|}{ Maternal age } \\
\hline $15-24$ & $65(13.3 \%)$ & $41(8.4 \%)$ & 1 & & \\
\hline $25-34$ & $147(30.0 \%)$ & $195(39.8 \%)$ & $0.429(0.21,0.89)$ & $1.92(1.20,3.09) *$ & 0.007 \\
\hline$\geq 35$ & $17(3.5 \%)$ & $42(8.6 \%)$ & $0.902(0.47,1.73)$ & $1.53(0.71,3.27)$ & 0.278 \\
\hline \multicolumn{6}{|l|}{ Maternal occupation } \\
\hline Housewife & $107(21.8 \%)$ & $180(36.7 \%)$ & $2.534(1.75,3.66)$ & $1.40(0.68,2.87)$ & 0.357 \\
\hline Others & $112(24.9 \%)$ & $91(16.5 \%)$ & 1 & & \\
\hline \multicolumn{6}{|c|}{ Husband's occupation } \\
\hline Farmer & $96(19.6 \%)$ & $167(34.1 \%)$ & $2.461(1.71,3.54)$ & $1.92(1.30,2.83) *$ & 0.001 \\
\hline Others & $133(27.1 \%)$ & $94(19.2 \%)$ & 1 & & \\
\hline \multicolumn{6}{|l|}{ Husband's education } \\
\hline Formal education & $191(39.0 \%)$ & $176(35.9 \%)$ & $2.465(1.62,3.75)$ & $1.49(0.92,2.41)$ & 0.105 \\
\hline $\begin{array}{l}\text { No formal } \\
\text { education }\end{array}$ & $38(17.3 \%)$ & $85(7.8 \%)$ & 1 & & \\
\hline Maternal education & & & & & \\
\hline Formal education & $187(38.2 \%)$ & $168(34.3 \%)$ & $2.427(1.57,3.75)$ & $1.36(0.83,2.24)$ & 0.227 \\
\hline $\begin{array}{l}\text { No formal } \\
\text { education }\end{array}$ & $42(8.6 \%)$ & $93(19.0 \%)$ & 1 & & \\
\hline
\end{tabular}

$*=\mathrm{P} \leq 0.05$ (significance level), $1=$ Reference.

Getting focused antenatal care service was nearly two time more likely among mothers with in the age group of 25-34 years than mothers within the age group 15-24 years $[\mathrm{AOR}=1.92,95 \% \mathrm{CI}=(1.20,3.09)]$. Likewise, those whose husband's occupation farmer were two times more likely utilized focused antenatal care service than their counter parts $[\mathrm{AOR}=1.92,95 \% \mathrm{CI}=(1.30,2.83)]$. Those mothers with empowerment were almost two times more likely utilized focused antenatal care service than mothers without empowerment $[\mathrm{AOR}=2.13,95 \% \mathrm{CI}=(1.43,3.20)]$.

\section{Discussion}

This study showed that focused antenatal care service utilization in Damot Sore Districtwas found to be $46.7 \%$. The finding was higher as compared with the studies conducted in Dejen and Aneded districts, in northwest Ethiopia (12.0\%) [11], and in Yem special District, south-western Ethiopia only $28.5 \%$ of women had effective antenatal care services during their last pregnancy [12]. This might be due to time difference, since 2009 a lot of health reform, construction of health infrastructure, and health promotion activities done well by health extension workers. However, this study finding is lower than study conducted in Ayder Kebele Mekelle city around $84.8 \%$ had four and above antenatal care contacts [13] and study conducted in West Sumatra, Indonesia in 2010 which is $80 \%$ [14] of respondents received ANC more than four times; this discrepancy might be due to discrepancy in study settings where this study is conducted in rural area but this two were in urban setting.

Mother's age was found statistically significant with focused antenatal care service utilization such that mothers within the age group of 25-34 were more likely got focused ante natal care service than mothers within the age group 1524 years. This finding was consistent with the studies conducted in South Africa [15] Ghana, Kenya and Malawi [16]. This might be due to mothers within this age group have many experience throughout their life time and receive education from health extension works consistently which can help them to resist the elders influence that can prevent them not to follow their FANC.

Husband's occupation was also found to be statistically significant with focused antenatal care service utilization of mothers. Mothers' whose husbands were farmers were more likely utilized focused antenatal care service than those mothers whose husbands were with other occupation. This might be due to health extension workers in rural setting of Ethiopia can access both mother and father simultaneously in their outreach program to provide health information dissemination regularly than those mothers whose their husbands are other than farmers.

Mothers who got empowerment from their husbands were more likely utilized focused antenatal care service than their counterparts. This might be due to their husband's empowerment encourages them to utilize ante natal care service and would reduce the work load of the pregnant mothersince they might share daily work load.

\section{Conclusion and Recommendation}

This study confirmed that focused antenatal care service utilization was low in the study area. This study also confirmed that among 490 interviewed mothers 229(46.7\%) were got focused antenatal care service. This study also 
identified that maternal age 25-34 years, husband's occupation and empowerment were the main factor influencing women follow-up of FANC during pregnancy. Thus strengthen the health information dissemination to husbands in order to empower their wives to get FANC service utilization and other services provided by health professionals during their pregnancy.

\section{Strengths and Limitations}

Selection of women's who gave birth in last six month prior to study to minimize the possible recall bias and use of simple random sampling in community based study was taken as strength. This study does not show cause and effect relationship between exposure variables and focused ante natal care service utilization due to the nature of study design.

\section{Competing Interests}

The authors declare that they have no competing interests.

\section{Acknowledgements}

We thank Wolaita Sodo University for funding this study. But the funding does not cover publication process. Study participants, data collectors, and supervisors are acknowledged for their cooperation during data collection.

\section{Author's Contribution}

$\mathrm{AB}$ was involved in conception, design, analysis, interpretation, report and manuscript writing. WF and $\mathrm{AL}$ were involved in the design, analysis, interpretation and report writing. All authors read and approved the final manuscript.

\section{References}

[1] Villar J (2001) WHO antenatal care randomized trial for the evaluation of a new model of routine antenatal care. 357: (1565-1570).

[2] Ministry of Health, Focused Ante Natal Care, Ministry of Health, Nairobi, Kenya, 2014.

[3] Central Statistical Agency and ORC Macro: Ethiopia Demographic and Health Survey 2011, Addis Ababa, Ethiopia and Calverton, Maryland, USA; 2012.
[4] WHO Maternal mortality ratio per100,000 live births. 2010; Available from: http://who.int/healthinfo/statistics/indmaternalmortality/en/ind ex.html.

[5] World Health Organization. Mother-baby package: implementing safe motherhood in countries. Geneva: WHO; 1996.

[6] The United Nations Children's Fund. Progress for Children: A Report Card on Maternal Mortality. p. 43, 2008, UNICEF, New York.

[7] World Health Organization, United Nations Children's Fund, United Nation Population Division, The World Bank. The World Trends in maternal mortality: 1990 to 2010.

[8] WHO, UNICEF, UNFPA, World Bank and United Nations Population Division, Geneva, Switzerland, 2014.

[9] Abosse Z, Woldie M, Ololo S (2010) Factors Influencing Antenatal Care Service Utilization in Hadiya Zone. Ethiop $J$ Health Sci. 20: 75-82.

[10] Mulat G, Kassaw T, Aychiluhim M (2015) Antenatal care service utilization and its associated factors among mothers who gave live birth in the past one year in Womberma District, North West Ethiopia. Epidemiology (Sunnyvale). S2: 003.

[11] Teshome Getachew et al, Focused Antenatal Care Service Utilization and Associated Factors in Dejen and Aneded Districts, Northwest Ethiopia, Primary Health Care 4:4, 2014.

[12] Bahilu Tewodros, Abebe g/Mariam, Yohannes Dibaba; factors affecting antenatal care utilization in yem special District, southwestern ethiopia; Ethiop J Health Sci. Vol. 19, No. 1 (March 2009).

[13] Kalayou K Berhe, Haftom G Welearegay, Gerezgiher B Abera, Hailemariam B Kahsay and Alemayehu B Kahsay, Assessment of Antenatal Care Utilization and its Associated Factors Among 15 to 49 Years of Age Women in Ayder Kebelle Mekelle City, American Journal of Advanced Drug Delivery, 2014, 062-075.

[14] Yenita Agus, and Shigeko Horiuchi Factors influencing the use of antenatal care inrural West Sumatra, Indonesia Agus and Horiuchi BMC Pregnancy and Childbirth 2012, 12:9.

[15] Myer L, Harrison A (2003) Why Do Women Seek Antenatal Care Late? Perspectives From Rural South Africa. The Journal of Midwifery \& Women's Health 48: 268-272.

[16] Pell C, Men aca A, Were F, Afrah NA, Chatio S, et al. (2013) Factors Affecting Antenatal Care Attendance: Results from Qualitative Studies in Ghana, Kenya and Malawi. PLoS ONE 8(1): e53747. doi: 10.1371/journal.pone.0053747. 